may be deep narrow channels with a rising gradient at both ends. Several of these channels are known in East Anglia; one seems to commence a few miles south of Cambridge, and follows approximately the line of the L.N.E.R. to Bishop's Stortford at least as far as Newport. It deepens rapidly southward, and if it is a normal river channel it must somewhere enter the sea, possibly following the Lea valley into the Thames estuary. If so, it might cause grave difficulty to engineering projects (as other such channels have done elsewhere), like that for a Thames tunnel east of the Lea valley. The buried channel of the Thames higher up is well known, but if the Newport channel does indeed enter the Thames estuary, its depth below sea-level would far exceed that of the known channel. It would therefore be of great interest both to geologists and engineers if such channels could be detected with certainty by geophysical methods.

The lecture briefly describes such applied geophysical methods, after discussing the scope of geophysics and the history and present position of the main 'pure' problems of geophysics. It should be added that the term geophysics is used in the lecture in a restricted sense : and such a remark as "geophysicists in this country do not concern themselves very much with the electric and magnetic field of the earth, which are observed in detail in various observatories", and the mention of the Carnegie Institution's Geophysical Laboratory without reference to the same Institution's great Department of Terrestrial Magnetism, must be interpreted as betokening unfamiliarity born of lack of personal interest in these further fields of geophysics.

\section{History of Bitumen}

$\mathrm{T}$ O-DAY, when petroleum with its vast range of derivatives is regarded as indispensable to the welfare of man, it is wholesome to be reminded of the salient factors which gradually extended its usefulness during the course of some five thousand years. It is equally salutary to have delineated handicaps of lack of knowledge, apparatus and facilities, which nevertheless were minimised by the ingenuity of ancient peoples who employed bitumen for a variety of purposes still recognised to-day.

A booklet entitled "The Story of Bitumen" (presumably by R. J. Forbes of Amsterdam, who last year contributed a similar article to the periodical Bitumen entitled "Aus der ältesten Geschichte des Bitumens") recently issued by Shell-Mex, Ltd., gives a brief account of the exploitation of bitumen from earliest records of its existence to about A.D. 1800 . Abundant deposits were known even to the most ancient civilisations inhabiting the region between the Nile valley and that of the Indus, but production was necessarily confined to surface operations by lack of knowledge of the technique of deep drilling and absence of geological information on deeper oil or rock-asphalt deposits. At the end of the period reviewed, in spite of vicissitudes which hindered rather than accelerated growth of the industry, particularly at the time of the later Roman Empire, the majority of deposits of which we now have knowledge were actually known. Then, however, the importance of petroleurn was negligible compared with present-day values, for the internal combustion engine which was later to give such tremendous impetus to the industry and create such a wide- spread demand for petroleum products was not yet discovered.

Records of actual production in ancient times are naturally scanty. It is obvious, however, that methods were extremely crude, as it is authentically reported that bitumen was recovered from the Dead Sea by men in rafts who simply 'hacked off' as large a piece of the floating mass as they could conveniently carry away. Similarly, until the eleventh century, only the most primitive attempts towards distillation were made : and this fact virtually excluded the use of light combustible oils. Gradually, however, more elaborate and practical methods were evolved, until at the beginning of the nineteenth century it may safely be said that the foundations of modern distillation technique were laid. Even so, no appreciable growth of the industry took place until after 1860, when deep drilling came within the realms of possibility. It is surprising, therefore, that in spite of all these handicaps and difficulties to easy production, we find bitumen was used extensively in antiquity as a building and road material, as a waterproofing agent and in various guises as a weapon in times of warfare. In comparatively recent times it was universally used also for lighting and heating purposes and as an ingredient of paints.

The booklet, in addition to tracing the story of bitumen, gives a chronological list of outstanding dates in the history of bitumen and includes a bibliography on petroleum and bituminous materials which, together with the numerous excerpts from early works quoted in the text, should provide a useful background to a historical study of the petroleum industry.

\section{University and Educational Intelligence}

BELFAST.-Dr. H. Barcroft, lecturer in physiology at University College, London, has been appointed to the Dunville chair of physiology in succession to Prof. T. H. Milroy, who is retiring on October 1. Dr. D. C. Harrison, lecturer in biochemistry in the University of Sheffield, has been appointed to the J. C. White chair of biochemistry, in succession to the late Prof. J. H. Milroy.

Colonel S. H. Browne, formerly of the Indian Medical Service, has bequeathed to the University $£ 10,000$ to found medical research scholarships.

Cambridge.-The Royal College of Veterinary Surgeons has intimated to the Vice-Chancellor that candidates who submit evidence that they are graduates in the Natural Sciences Tripos and that in the course of their examination they have passed in physiology, pathology, biochemistry and anatomy, may be exempted from the second examination conditionally on their passing the prescribed examination in animal management before the third examination.

At St. John's College, F. J. S. Hollick has been elected into a fellowship.

OxFond.-The Halley Lecture will be delivered on June 5, at 5 p.m. in the Lecture Theatre at the University Museum by Dr. J. S. Plaskett, director of the Dominion Astrophysical Observatory, Victoria, B.C., Canada, who will take as his subject: "Dimensions and structure of the Galaxy."

Mr. J. N. L. Baker has been appointed University reader in historical geography for seven years from October 1. Miss B. M. Blackwood has been 
reappointed university demonstrator in ethnology for one year from October 1.

A reader in statistics is to be appointed for five years from the first day of Michaelmas Term, 1935, the warden and fellows of All Souls having undertaken to provide a stipend of $\mathfrak{£ 6 0 0}$ a year for that period.

In continuation of his course of lectures on the scientific contributions of members of the Oxford colleges, Dr. R. T. Gunther, reader in the history of science, in a recent lecture directed special attention to the work of Robert Plot, John Radcliffe and Edmund Cartwright, all of University College, and respectively a great natural historian, a most munificent benefactor and an eminent inventor. At the same time the lecturer expressed his regret that the present Radcliffe Trustees should not have considered it their duty as managers of a charitable trust to preserve intact the historical scientific library of Prof. Stephen Rigaud, which they had purchased for far less money than it has now realised in a public sale-room.

UNEMPLOYMENT among young university graduates formed the subject of the deliberations of the Committee of International Students' Organisations at its meeting on April 10-1I. As regards the possibilities of limiting the attendance of students at universities, the Committee urged that it would be both harmful and dangerous to endeavour to place restrictions on those who could rightly claim to attend the universities, and it disapproved of the imposition of a bar against women or against certain classes of the population on grounds of race or opinion. As a remedy for unemployment among intellectual workers, it recommended the establish. ment of university and professional information centres in the various countries, and suggested that public authorities or mutual aid societies should undertake the direction of certain branches of intellectual work for which private individuals have not the means to provide. Further, it suggested the adoption of measures by universities or student organisations for training young intellectual workers for their professions in country districts or colonies such as the 'social groups' in France, the 'educational missions' in Spain, or the 'frontier colleges' in Canada. Another recommendation was that bilateral or plurilateral agreements should be framed regarding the equivalence of university degrees, the exercise of professions abroad, and the employment of intellectual workers in foreign countries. The Committee urged international organisations of students and intellectual. workers to consider the possibility of establishing an international organisation for securing work on the basis of the general information which might be supplied by the International Labour Office.

\section{Science News a Century Ago}

\section{University of London}

On May 18, 1835, The Times said, "Yesterday the annual distribution of the medals and prizes to the successful candidates in the medical and surgical departments took place at the London University; Lord Nugent presided on the occasion. . . . Immediately after the distribution of the prizes the Chairman rose and addressed the company. His lordship had been about three years from London. At his departure the London University was in a state of infancy; at his return he had been highly gratified on finding that it had made so rapid a growth towards maturity. Mr. Thomas Campbell, who had first suggested the foundation of the present establishment, had said, that only two capital cities of Europe had been without universities, London and Constantinople. The reproach was now removed from London, in which two most useful institutions flourished, not in a spirit of opposition to each other, but in a spirit of laudable emulation and generous rivalry."

\section{Progress of Mechanics' Institutions}

At the anniversary meeting of the London Mechanies' Institution (now Birkbeck College) held on May 20, 1835, the president, Dr. Birkbeck, is reported to have said that "This establishment was still flourishing, and those elsewhere were becoming more numerous and more prosperous. The most remarkable circumstance connected with the prosperity of mechanics' institutions was the establishment of one at Cambridge, which had received the approbation and patronage of all the great and the wise of that distinguished seminary of learning. . . . Endeavours had been made to establish a mechanics' institution at a place near Bolton, but he (Dr. Birkbeck) had received a letter from the person who made the attempt, stating that the mean rate of wages was only $7 s$. a week, and although the subscription had been dropped from $10 s$. a year to $6 s$, he could get no subscriptions, nor any donations. . . . At Manchester and Liverpool, however, the progress of these insti. tutions had been great. . . . The number of members belonging to the metropolitan institution was 1,123 exclusive of honorary members; that of Manchester, including honorary members, was 1,232 , and that of Liverpool including honorary members, was 1,206."

\section{Theory of Respiration}

At a meeting of the Royal Society on May 21 , 1835 , Dr. William Stevens read the concluding portion of his paper on observations on the theory of respiration. After reviewing the author's remarks on the interaction of the air and the blood and the experiments with which the paper was accompanied, the report in the Society's Abstracts said : "According to these views it is neither in the lungs, nor generally in the course of circulation, but only during its passage through the capillary system of vessels, that the blood undergoes the change from arterial to venous; a change consisting in the formation of carbonic acid, by the addition of particles of carbon derived from the solid textures of the body, and which had combined with the oxygen supplied by the arterial blood; and it is by this combination that heat is evolved, as well as a dark colour imparted to the blood. The author ascribes, however, the bright red colour of arterial blood, not to the action of oxygen which in itself is completely inert as a colouring agent, but to that of the saline ingredients naturally contained in healthy blood. On arrival at the lungs, the first change induced in the blood is effected by the oxygen of the atmospheric air, and consists of the removal of the carbonic acid, which had been the source of the dark colour of the venous blood; and the second consists in the attraction by the blood of a portion of the oxygen, which it absorbs from the air and which takes the place of the carbonic acid." 